ARTICLE

\title{
Nitrogen starvation reveals the mitotic potential of mutants in the S/MAPK pathways
}

\author{
Rostyslav Makarenko (10) 1,2,3, Claire Denis ${ }^{1,3}$, Stefania Francesconi (1) 1,3, Serge Gangloff (1) ${ }^{1}$ \& \\ Benoît Arcangioli iD ${ }^{1 凶}$
}

The genetics of quiescence is an emerging field compared to that of growth, yet both states generate spontaneous mutations and genetic diversity fueling evolution. Reconciling mutation rates in dividing conditions and mutation accumulation as a function of time in non-dividing situations remains a challenge. Nitrogen-starved fission yeast cells reversibly arrest proliferation, are metabolically active and highly resistant to a variety of stresses. Here, we show that mutations in stress- and mitogen-activated protein kinase (S/MAPK) signaling pathways are enriched in aging cultures. Targeted resequencing and competition experiments indicate that these mutants arise in the first month of quiescence and expand clonally during the second month at the expense of the parental population. Reconstitution experiments show that S/MAPK modules mediate the sacrifice of many cells for the benefit of some mutants. These findings suggest that non-dividing conditions promote genetic diversity to generate a social cellular environment prone to kin selection.

\footnotetext{
${ }^{1}$ Genome Dynamics Unit, Institut Pasteur, UMR3525 CNRS, 75015 Paris, France. ${ }^{2}$ Sorbonne Université, École Doctorale 515,75005 Paris, France. ${ }^{3}$ These authors contributed equally: Rostyslav Makarenko, Claire Denis, Stefania Francesconi. ${ }^{\infty}$ email: benoit.arcangioli@pasteur.fr
} 
$\mathrm{n}$ nature, cells alternate between replicative and nonreplicative states depending on the fluctuating environmental conditions and physiological requirements ${ }^{1}$. The reversible non-replicative state resulting from cell division arrest or transition to a more specialized cellular type is predominant in nature and termed quiescence or G0. The transition between replicative and non-replicative states is interpreted by the cell as a stress that requires a quick response for survival. Therefore, the cells have evolved mechanisms to cope with the perpetual fluctuation of their habitat through optimized genetic and epigenetic regulations that allow a rapid metabolic adaptation, coordinate developmental programs, and tissue homeostasis to ensure longevity.

Several aspects of quiescence have been studied in both budding (Saccharomyces cerevisiae) and fission (Schizosaccharomyces pombe) yeast. These include a decrease in transcription, translation and metabolism, cell cycle arrest, activation of autophagy, an increase in the resistance to a large variety of stresses ${ }^{2}$, as well as a variation in telomere length and in RNA interference functions in S. pombe $e^{3-5}$.

In the laboratory, chronological lifespan is traditionally studied by measuring the viability over time of cells having reached the stationary phase after exhaustion of the carbon source from an otherwise nitrogen-rich medium ${ }^{6,7}$. The stationary phase by glucose exhaustion ${ }^{8,9}$, as well as starvation by iron ${ }^{10}$, sulfur ${ }^{11}$, phosphate ${ }^{12}$, or transfer to water ${ }^{13}$ is rarely used to study longterm quiescence in fission yeast because cells die rapidly. Alternatively, nitrogen starvation has been extensively used to study mating, meiosis, and quiescence in fission yeast ${ }^{13,14}$. Under these conditions, the TOR (target of rapamycin) and the SAPK (stressactivated protein kinases) pathways set off two rapid cell divisions with no cell growth to arrest cells in G1 and promote the expression of pheromones ${ }^{2,13-16}$. When both mating-type partners are present, the mating and the meiotic programs are engaged, whereas in the absence of a partner cells enter $\mathrm{G}^{2}, 15$. The quiescent state can be sustained for prolonged periods and provides a unique opportunity to analyze the outcome of timedependent processes involved in quiescence entry, maintenance, and exit ${ }^{14}$. Thus, nitrogen starvation is a simple system to induce differentiation and a valuable complementary approach to study biological aging in quiescence ${ }^{17}$.

The S/MAPKs (stress or mitogen-activated protein kinases) signaling pathways are required for sensing and responding to internal and external stimuli and various environmental stress. This fast response involves a cascade of kinases that controls basic

\begin{tabular}{|c|c|}
\hline Strain & Relevant Genotype \\
\hline PB1623 & MsmtO \\
\hline $972 \mathrm{~h}^{-}$ & $h^{-}$ \\
\hline PB2262 & Msmt0 SPBC31A8.02::mCherry::KanR \\
\hline PB2740 & Msmt0 win1-394 +13 bp SPBC31A8.02:: mCherry:KanR \\
\hline PB2741 & Msmt0 mkh1-2929 -10 bp SPBC31A8.02::mCherry::KanR \\
\hline PB2850 & PA17 sty1-G197T SPBC31A8.02::mCherry::KanR \\
\hline PB2851 & Msmt0 sty1-C74G SPBC31A8.02::mCherry::KanR \\
\hline PB2739 & Msmt0 sgf73-896+T SPBC31A8.02::mCherry::KanR \\
\hline PB2532 & Msmt0 sgf73-896 +T \\
\hline PB2921 & Msmt0 sty1-G197T \\
\hline PB2926 & Msmt0 sty7-C74G \\
\hline PB2928 & Msmt0 pmk1-153 +A \\
\hline PB2310 & Msmt0 sty14::ura4+ \\
\hline PB3242 & Msmt0 mkh1-640 +A \\
\hline PB2932 & Msmt0 win1-1086 -G \\
\hline PB2933 & Msmt0 win1-394 +13 bp \\
\hline PB2457 & $P \Delta 17$ win $1 \Delta:: K a n R$ \\
\hline
\end{tabular}

biological processes ${ }^{18}$. The SAPK module is composed of the MAPKKKs Win1 and Wis4, the MAPKK Wis1 and MAPK Sty1/ Spc1. Early work has identified Styl and Wis1 as essential genes to arrest the cell cycle in G1, enter in quiescence, and maintain viability $^{16}$. The MAPK module, required for cytokinesis and cell wall integrity, is composed of Mkh1 (MAPKKK), Pek1 (MAPKK), and Pmk1 (MAPK) ${ }^{19}$. Although it was reported that Pmk1 participates in Styl activation of the downstream effector Atf1 (ref. ${ }^{20}$ ), the crosstalk between the SAPK and MAPK modules is not fully understood. Unfortunately, the inability of the SAPK deletion mutants ${ }^{2}$ to efficiently enter G0 has precluded from addressing whether the SAPK pathways participate in stress resistance during quiescence as well.

During growth, spontaneous mutations accumulate as a function of cell division ${ }^{21}$ or DNA replication ${ }^{22}$. Under growth conditions, genome-wide sequencing approaches have shown that the mutation rate is in the range of $2 \times 10^{-10}$ mutation per nucleotide and per generation in fission yeast ${ }^{23,24}$. Extensive work in many species has shown a similar mutation spectrum where singlenucleotide variants (SNVs) are more frequent than insertions and deletions (indels) during growth ${ }^{25}$. In quiescence, DNA damage is efficiently repaired indicating that some repair pathways are functional ${ }^{11,26}$ and we recently showed that mutations increase linearly as a function of time, starting on day 1 (ref. ${ }^{27}$ ). When the medium was replaced every other week to avoid the accumulation of nitrogen released by dead cells, we found a random distribution of mutations that reached 0.6 mutations per genome after 3 months of quiescence, with about one half of the strains exhibiting no detectable mutation. In addition, and unlike cycling cells, SNVs and indels accumulate at the same pace and deletions dominate insertions, a signature that we called chronos ${ }^{27}$. Thus, the genetics of quiescence fulfills the experimental conditions to select for de novo mutations that sustain viability in non-dividing conditions and explore a different mutation spectrum than screens using deletion libraries or conditional mutants ${ }^{28}$.

The goal of this study is to select for spontaneous mutants appearing in nitrogen-starved fission yeast cells that are capable of resuming growth after 2 and 3 months of quiescence. Using WGS, we find recurrent de novo mutations in genes directly related to the S/MAPK pathways. Targeted resequencing and competition experiments indicate that these mutants expand clonally at the expense of the parental cell population. Thus, we uncover an unexpected scavenging function that mediates the sacrifice of many cells for the benefit of some mutants during quiescence. Comparisons between the genetics of quiescence of bacteria, yeast, and mammalian cells are discussed.

\section{Results}

The S/MAPK mutants are enriched among survivors. To explore the potential of the genetics of quiescence we grew a haploid prototrophic strain (Table 1) in minimum medium (EMM) for 27 generations, enough to produce $10^{8}$ cells and limit the occurrence of mutations. The culture is then transferred to minimum medium without nitrogen at low cell density $\left(10^{6}\right.$ cells per $\mathrm{mL}$ ) and kept in non-proliferative conditions for 3 months without changing the medium (Methods). Based on previous work establishing somatic and quiescence mutation rates $23,24,27$ and our experimental settings reducing somatic mutations, we anticipated 0.6 mutations per genome, generated mainly during the 3 months of starvation. The viability curve (Fig. 1a) shows three phases; during the first 20 days, the viability is maintained (phase I), followed by a rapid decline (phase II), before slowly stabilizing (phase III). Fluorescent-activated cell sorting (FACS) analysis of PB1623 indicates that cells with no DNA accumulate over time (Fig. 1b). The fraction of dead cells correlates with the 

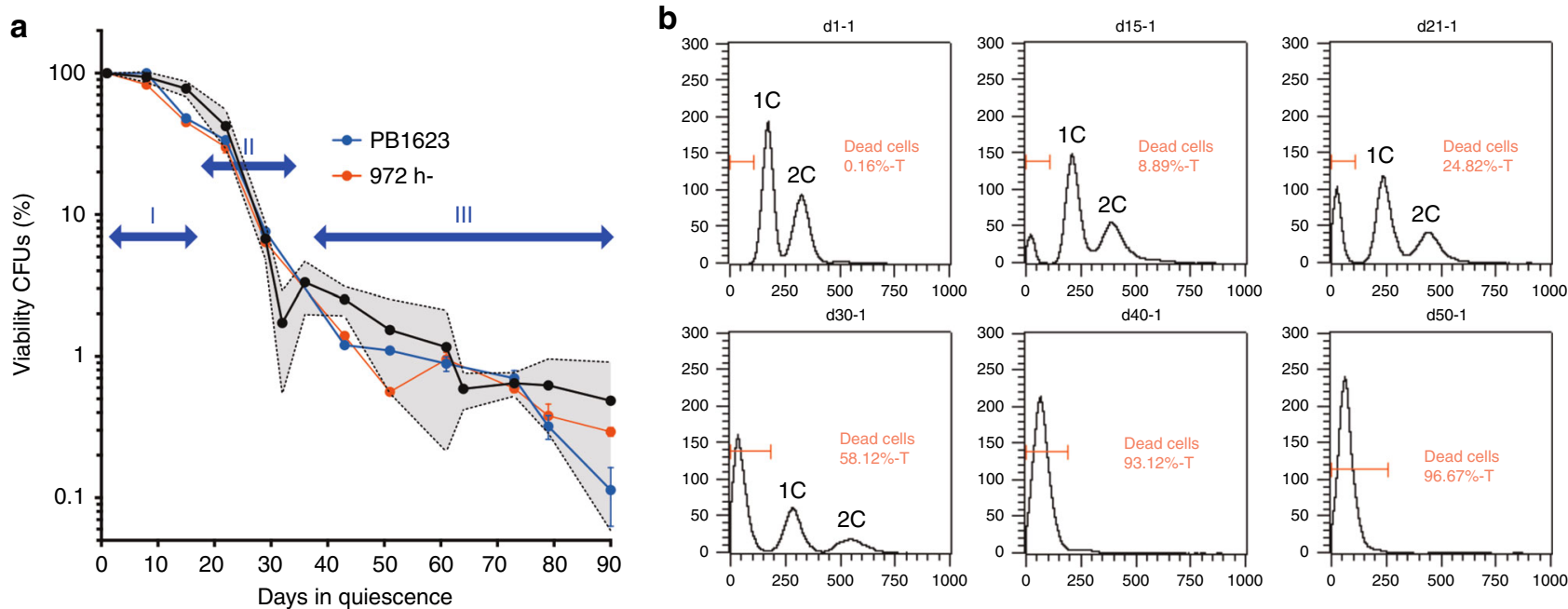

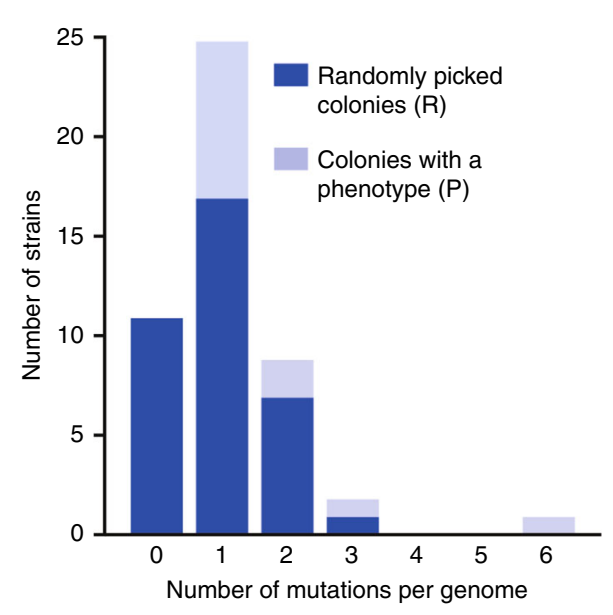

d

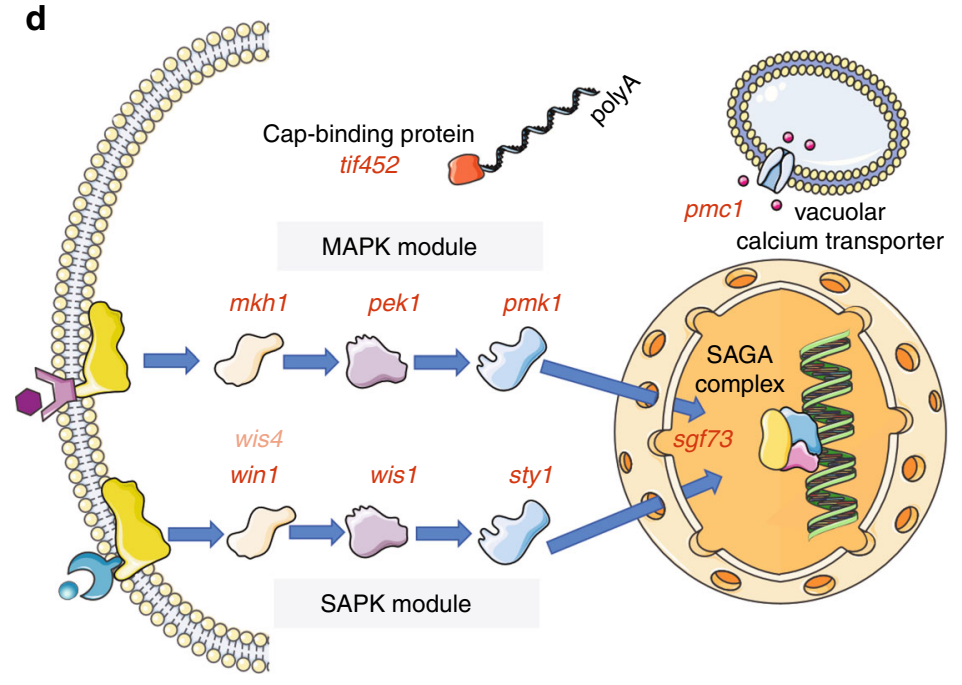

Fig. 1 Viability and distribution of mutations in nitrogen-starved cultures. a The ability to form colonies (CFUs) was monitored on 17 independent cultures for 3 months by plating aliquots of the cultures on rich medium at various time points (black curve). The mean is represented and the gray area delineates the limits of the standard deviations. The red (wild-type reference strain $972 \mathrm{~h}^{-}$) and blue (our wild-type progenitor PB1623) curves were made in parallel on a culture that was split into three on day 1 of quiescence. The CFUs were determined in triplicate at days 21, 61,73, 79, and 90. The three phases are highlighted. Source data are provided as a Source Data file. b Analysis of the DNA content of PB1623 cells determined by FACS at 1, 15, 21, 30, 40, and 50 days of starvation. c Distribution of the number of mutations per genome after 3 months of starvation in the 36 randomly picked (R) colonies and in the 12 colonies selected for their sensitivity to various agents. $\mathbf{d}$ Schematic representation of the pathways in which the nine genes analyzed in this study operate.

capacity of the culture to form colonies (CFUs). When the medium was replaced every other week ${ }^{27}$, phase III was not observed and cells continued losing viability. The presence of phase III is also observed in the unrefreshed culture of the $972 \mathrm{~h}^{-}$reference strain (Fig. 1a, Table 1). This indicates that phase III depends on the experimental conditions and not on the genetic polymorphism (Supplementary Table 1) between the two strains. Thus, the presence of phase III suggests a phenotypic adaptation of the cells in the surviving population. Accordingly, when we monitored the sensitivity of the survivors to conditions affecting a broad range of cellular functions, we found 30 clones out of 150 (20\%) exhibiting a phenotype after 3 months (Methods and Supplementary Table 2). Genetic backcrosses followed by tetrad analysis indicate that the 30 strains exhibit a Mendelian 2:2 segregation of the phenotype indicating a defect at a single locus for each strain (Supplementary Fig. 1a, b). This elevated level of surviving cells exhibiting a sensitivity phenotype was not expected with the anticipated level of mutation and suggests a strong gain of fitness.
To estimate the accumulation of mutations and identify some of the genes mutated, we sequenced the genome of 12 strains selected for their sensitivity to various conditions as well as of 36 survivors picked randomly. We found 22 mutations in the genome of the 12 clones selected for their phenotype and 8 out of 12 strains contain a single mutation indicating that this mutation is likely responsible for the phenotype (Fig. 1c, Supplementary Methods). Although one strain contains four mutations in a mischaracterized gene (SPCC569.02c-antisense-1), mutations in clusters are rare but have been previously observed ${ }^{29}$. We also identified 36 mutations in the 36 strains picked randomly, among which 16 are in genes belonging to the S/MAPK pathways ${ }^{16,19}$, to their downstream targets eIF4E/CAP-binding factor Tif452 (ref. ${ }^{30}$ ) and Sgf73 coding for a subunit of the SAGA transcriptional complex ${ }^{31,32}$. We also found Pmc1, the vacuolar calcium transporter, that is remotely related to the S/MAPK pathways and whose absence makes cells sensitive to calcium and rapamycin under salt stress ${ }^{33,34}$ (Fig. 1c, d, Supplementary Tables 3 and 4). 
Other mutations in genes including cut1, gap1, papb, and pfl4 were also identified, but were not further studied in this work (Supplementary Table 3). The extent of mutations present after 3 months of quiescence is about two-fold that previously reported, and their spectrum is consistent with chronos ${ }^{23,27}$.

Targeted resequencing of long-term survivors. The number and frequency of alleles that we found prompted us to analyze the occurrence of S/MAPK mutations over time using a deep targeted sequencing approach of eight genes identified above; wis1 was not included in this round (Fig. 1d and Methods). We first analyzed the culture from which the mutants were isolated (thereafter called culture 0 ) along with three additional independent cultures (1-3) on day 1 and after 2 and 3 months of quiescence, providing a readout of the dynamics of the S/MAPK mutants in the cell population (Fig. 2a left, Methods).

Mutations in the targeted genes (Fig. 1d) are detected in the four cultures and account for $17.7-64.7 \%$ of the surviving cell population (Fig. 2b, c, Supplementary Table 5, Methods and Supplementary Methods), whereas none are detected above $0.1 \%$ with a coverage of at least 5000 on day 1 . Between 2 and 3 months, the distribution of alleles in each culture is fluctuating. For example, in culture 2 the sgf73-896 + T allele represents $9.6 \%$ of the population at 2 months of starvation and reaches $43.5 \%$ a month later, indicating cell division, at the expense of $m k h 1-640$ $+\mathrm{A}$. Conversely, in culture 3 the proportion of win 1 alleles remains stable over the same time frame. These observations indicate that each mutant behaves individually in the population, and that clonal interference can affect the ability to undergo cell division and impact the fitness of the alleles (Fig. 2b, c). The sgf73-896 + T and $m k h 1-640+\mathrm{A}$ alleles are found in several cultures and the mutations are located in stretches of 8 As and 7 As, respectively. The mutation win 1-1273 $+17 \mathrm{bp}$, previously reported $^{35}$, and win 1-394 +13 bp are direct-repeat duplications of 17 and 13 bp, respectively (Fig. 3b, Supplementary Table 5). To validate our calling procedure, we went back to the frozen samples (Methods) to isolate several clones exhibiting a phenotype and confirm by Sanger sequencing the presence of the corresponding mutations (alleles in red in Fig. 2, Supplementary Table 5 and Methods).

Mutations occur in nitrogen starvation. The large proportion of indels is reminiscent of the chronos signature ${ }^{27}$ and supports the view that many mutations arise during prolonged nitrogen starvation. We reasoned that the mutations arising during growth will be maintained in similar proportions over time. Thus, if a culture is divided on day 1 of quiescence into subcultures, it should be possible to distinguish preexisting mutations that will be present in several subcultures from unique mutations that have occurred independently during the quiescence period. To address this issue, we grew a culture from a single fresh colony that was transferred to EMM-N for 1 day prior to being dispatched into six subcultures containing $10^{7}$ cells each (Fig. $2 \mathrm{a}$, right panel). In this experiment, we analyzed one thousand colonies from day 1 before splitting and from each subculture at 2 months of starvation. The nine genes, including wis1, were PCR amplified in duplicate from each subculture and were Illumina sequenced separately. Thus, the sensitivity of our calling procedure was improved by increasing the coverage and collecting the cells only at 2 months (Methods). Like in the four independent cultures, the proportion of mutations in the targeted genes in the six subcultures ranged from $19.5 \%$ to $50.9 \%$ (Fig. 2d, Supplementary Table 5) at 2 months, whereas no mutation was detected above $0.1 \%$ on day 1. The most frequent alleles are sty1-C545T and sty1-A553T and are restricted to subcultures 5 and 2, respectively. Several hotspot mutations found in the previous experiments $(m k h 1-640+\mathrm{A}$, win 1-1273 +17 bp, and win1-394 +13 bp) are found again in some but not all subcultures. If we exclude the hotspots, the vast majority of the other alleles in each subculture are unique, strongly supporting the model in which the largest part of the mutations arises independently during nitrogen starvation (see Discussion).

Stress resistance in quiescence requires the SAPK pathway. Using the approach described above, we identified 195 independent mutations in nine genes (Fig. 3a). When their spectrum was analyzed, different distributions of variants were observed (Fig. 3a, b). While frameshift indels or nonsense mutations are found in the MAPK genes, it is remarkable that the genes in the SAPK alleles only contain missense or in frame indels, with the notable exception of the Win 1 upstream kinase. However, this latter function could be compensated for by Wis4, a related MAPKKK (Fig. 1d). These data strongly suggest that some functions of the SAPK pathway cannot be eliminated in quiescence.

Since it is well established that sty $1 \Delta$ deletion strains enter and survive poorly in quiescence ${ }^{16}$, we tested whether the 2 sty 1 alleles identified by sequencing the 48 strains (Supplementary Table 3) are proficient to enter G0.

We found that both alleles are capable of entering quiescence although slower than wild-type (Fig. 4a, b). This unique property prompted us to address whether the SAPK pathway is also required to respond to stress during quiescence, and found that the sty 1 mutations are sensitive to temperature and $\mathrm{H}_{2} \mathrm{O}_{2}$ both in vegetative and quiescent cells (Fig. $4 \mathrm{c}-\mathrm{f}$ ). The comparison with the deleted strain, which is only possible in growing cells, supports the prediction that these alleles are hypomorphic (Fig. 4c-f). On the contrary, as predicted by their mutation spectrum, the win 1 alleles behave like the deletion (Fig. 4c-f). These results indicate that the SAPK pathway is required to confer the widely conserved elevated stress resistance observed at least in early quiescent cells ${ }^{14}$, but hampering its function provides an advantage upon exit from prolonged starvation.

Growth advantage under nitrogen starvation. To determine the advantage conferred by the mutants in nitrogen-starved conditions, we first compared the viability of the wild-type parental strain with several mutants in the S/MAPK modules during longterm starvation. The survival profile of $m k h 1-2929-10 \mathrm{bp}$ and sgf73-896 + T mutant strains is similar to the parental wild-type strain while that of win1-394 +13 bp, sty1-C74G and sty1-G197T decreases rapidly until it roughly reaches $1 \%$ (Fig. 5a, Table 1). These data suggest that the advantage may only manifest itself through cooperation in a heterogeneous cellular population ${ }^{36}$. To test this idea, we set up competition experiments using cultures containing the wild-type and one of the mutant strains, as previously performed in bacteria to define the Growth Advantage in Stationary Phase (GASP) phenotype ${ }^{37}$. After 1 day of quiescence, we mixed $99.9 \%$ wild-type and $0.1 \%$ kanamycin marked strains (Methods, Table 1). In the co-culture conditions, the win1-394 +13 bp, sty1-C74G, sty1-G197T, mkh1-2929 - 10 bp, and sgf73$896+\mathrm{T}$ marked mutant strains reveal their mitotic potential. During the initial 20-30 days, the mutants die with kinetics similar to that of the individual cultures (Fig. 5b). Subsequently, the mutants start to proliferate exponentially with a generation time of about one division every 3 days. The SAPK mutants end up forming a population larger than their initial inoculum to outcompete the wild-type at 2 months of starvation (Fig. 5b). The simplest hypothesis to account for this result is that the progressive death of the cells (mainly the wild-type 
a
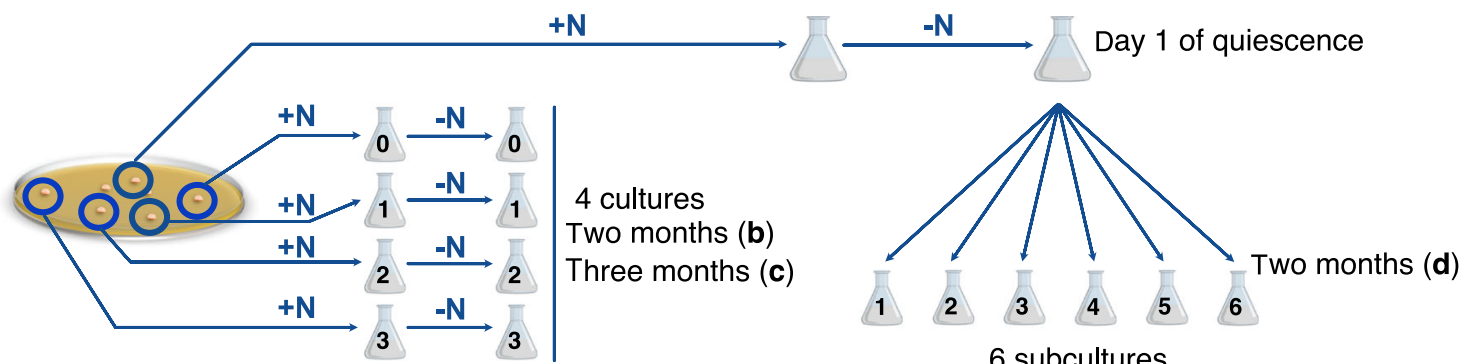

6 subcultures

b

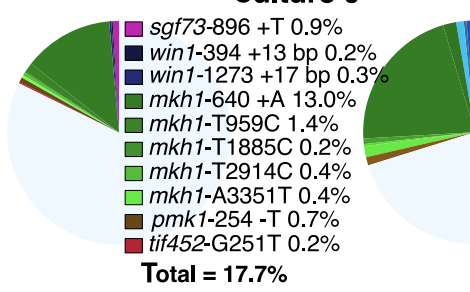

Culture 1 win $1-1273+17$ bp $0.3 \%$ $\square$ win $1-3010+$ A $0.9 \%$ $\square$ sty $1-216+9$ bp $0.4 \%$ $\square$ sty 1 -G647C $1.1 \%$ mkh1-A639G 1.9\% $m k h 1-640+\mathrm{A} 21.3 \%$ $m k h 1-640+\mathrm{A} 21.3 \%$
$m k h 1-\mathrm{C} 2378 \mathrm{G} 0.8 \%$ $\square m k h 1-\mathrm{A} 3138 \mathrm{C} 0.3 \%$ $\square m k h 1-3219-18 \mathrm{bp} 1.6 \%$ pmk1-G497T 1.2\%

Total $=\mathbf{2 9 . 8} \%$

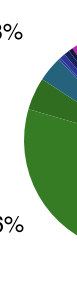

\section{Culture 2}

sgf73-896 +T $9.6 \%$ win $1-393+13$ bp $0.6 \%$

win $1-\mathrm{C} 813 \mathrm{~A} 0.8 \%$ win $1-2339$ - 5 bp $0.8 \%$ win 1 -T2381G $0.3 \%$ sty $1-\mathrm{G} 188 \mathrm{C} 3.7 \%$ sty1-G188C 3.7\% $m k h 1-G 250 T$
$m k h 1-640+A$
$27.0 \%$ $m k h 1-640+A$
$m k h 1-2517+14$ bp $1.2 \%$ mkh1-G3145T $0.2 \%$ pmk1-251-A $1.7 \%$

pmk1-G592A 2.5\% pmk $1-1097-16$ bp $10.4 \%$ $\square$ pmc1-2441 +18 bp $1.2 \%$

Total $=64.7 \%$

\section{Culture 3 \\ Culture 3}

win $1-394+10$ bp $1.6 \%$

win $1-504-\mathrm{A} 1.7 \%$

win $1-2363-13$ bp $3.8 \%$

win $1-3680-\mathrm{A} 3.5 \%$

$\square$ win 1 alleles $<1 \%=3.9 \%$

mkh1-236 -A 1.2\%

mkh1-640 +A $15.8 \%$

$\square$ mkh-CT1884TG $0.2 \%$

$\square m k h 1-2254+\mathrm{T} 0.7 \%$

mkh1-G3124T 0.2\%

mkh1-T3137G 0.5\%

pmk1-435 -TA $0.7 \%$

$\square$ pmk1-902 +14 bp $0.2 \%$

Total $=\mathbf{3 4 . 0} \%$

\section{Culture 2}

c

Culture $\mathbf{0}$

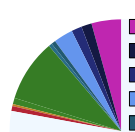

sgf73-896 + T 4.3\% win $1-1273+17$ bp 1.5 7 win1 alleles $<1 \%=$ sty $1-C 74 \mathrm{G} 0.6 \%$ win $1-394+13$ bp $1.5 \%$ sty1-G197T 0.5\% $\square m k h 1-640+\mathrm{A} 9.0 \%$ mkh1-T959C $0.9 \%$ pmk $1-1091+26$ bp $0.3 \%$ $\square$ tif452-G251T $0.7 \%$ Total $=22.1 \%$
Culture 1 win1-C2668T $1.2 \%$ $\square$ win $1-3010+$ A $1.2 \%$ sty $1-216+9$ bp $1.8 \%$ $m k h 1-640+\mathrm{A} 10.2 \%$
$m k h 1-3219-18$ bp $0.2 \%$ $\square$ mkh1-3219-18 bp 0. Total $=\mathbf{2 0 . 7} \%$

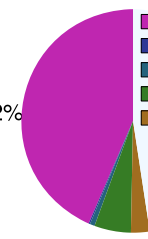

sgf73-896 + T $43.5 \%$ win $1-2339-5$ bp $0.2 \%$ sty $1-\mathrm{G} 188 \mathrm{C} 0.7 \%$ $m k h 1-640+\mathrm{A} 5.3 \%$ pmk1-G592A $2.7 \%$ Total $=\mathbf{5 2 . 4} \%$

\section{Culture 3}

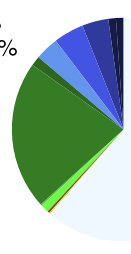

win $1-394+10$ bp $1.1 \%$ win1-504 -A $1.1 \%$ win $1-2363-13$ bp $3.8 \%$ $\square$ win $1-3680$-A 4.4\% 6 win 1 alleles $<1 \%=3.4 \%$ $m k h 1-236-\mathrm{A} 1.4 \%$ $m k h 1-640+A 21.5 \%$ $m k h 1-2593+38$ bp $0.2 \%$ $m k h 1-3340-\mathrm{A} 1.2 \%$ pmk1-435-TA $0.3 \%$ $\square$ pmc1-G280T 0.2\% Total $=38.6 \%$ a

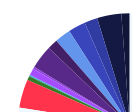

Subculture 1 win 1-357-Complex-1.2\% win $1-394+13$ bp $3.4 \%$ win $1-\mathrm{T} 2478 \mathrm{~A} 1.8 \%$ win $1-3010+\mathrm{A} 2.5 \%$ 10 win1 alleles $<1 \%$ wis 1 -T1108G $3.4 \%$ wis 1-A1493G 0.3\% $\square$ wis $1-1740+\mathrm{T} 1.0 \%$ $\square$ sty 1 -T562C $0.2 \%$ $\square m k h 1-640+\mathrm{A} 0.6 \%$ $\square$ tif452-G390T 4.3\% Total $=\mathbf{2 3 . 1} \%$

Subculture 5

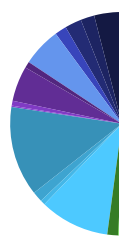
win $1-394+13$ bp $4.0 \%$ win $1-1024-\mathrm{C} 2.0 \%$ win $1-1265-5$ bp $2.4 \%$ win $1-3010+\mathrm{A} 1.8 \%$ 13 win1 alleles $<1 \%=6.3 \%$ wis 1-T1088G 1.0\% wis1-T1182G $5.2 \%$ Wis 1 -G1427 $0.7 \%$ Wis 1-G1430A 0.2\% $\square$ sty $1-C 545 \mathrm{~T}$ 13.2\% sty1-G646A $0.7 \%$ sty 1 -T659A $10.2 \%$ mkh1-3294 -9 bp 0.2\%

Total $=\mathbf{5 0 . 9} \%$
Subculture 2 win $1-394+13$ bp $2.4 \%$ win1-G1100A $1.0 \%$ $\square$ win1 alleles $1.2 \%$ wis $1-\mathrm{T} 1380 \mathrm{~A} 4.6 \%$ $\square$ wis 1-T1511G 1.0\%
$\square$ sty $1-A 553 T 12.5 \%$ Total $=\mathbf{2 3 . 8} \%$

\section{$4 \%$}

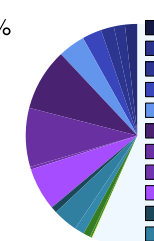

Subculture 3

win $1-1273+17$ bp $1.8 \%$ win $1-1877-\mathrm{T} 1.6 \%$ win $1-2179+17 \mathrm{bp} 1.8$ $\square$ win $1-3010+\mathrm{A} 2.8 \%$ 9 win 1 alleles $<1 \%$

wis1-T944G $9.2 \%$

wis 1-CC1281TT 8.5\%

wis 1-A1329T $0.4 \%$

sty $1-A 1 \mathrm{G} 1.0 \%$

sty 1 -G481T $3.5 \%$

sty $1-\mathrm{T} 535 \mathrm{C} 1.4 \%$

mkh1-640 +A 1.0\%

mkh1-T1885C $0.2 \%$
$\square$ pmc1-1293 -4 bp $0.1 \%$

Total $=\mathbf{4 4 . 7} \%$

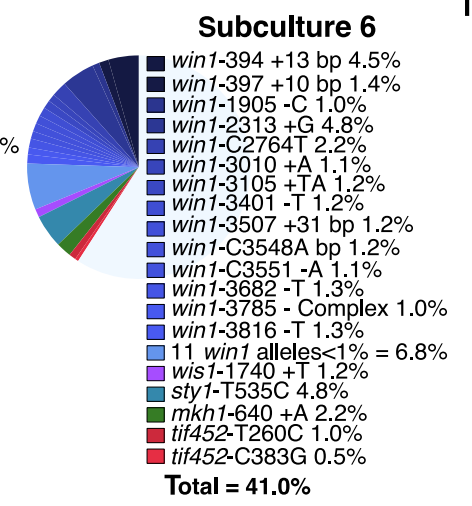

Fig. 2 Targeted resequencing of genes in the S/MAPK pathways. a Schematic view of the strategy used to obtain nitrogen-starved cultures. The same progenitor strain was used to grow $(+\mathrm{N})$ three independent cultures (in addition to culture 0 ) prior to shifting to quiescence $(-\mathrm{N})$ (left panel). The same approach was used to grow a single culture prior to splitting on day 1 of quiescence into six parallel subcultures (right panel). Samples were analyzed after 2 and 3 months of starvation. $\mathbf{b}$ Distribution and percentage of mutations found in the thousand colonies picked from cultures 0 to 3 after 2 months. The alleles in red were confirmed by Sanger sequencing the stress-sensitive colonies found among 120 cells plated out from the frozen pools. $\mathbf{c}$ same as $\mathbf{b}$ after 3 months. d Distribution and percentage of mutations in the subcultures after 2 months of starvation. 
a

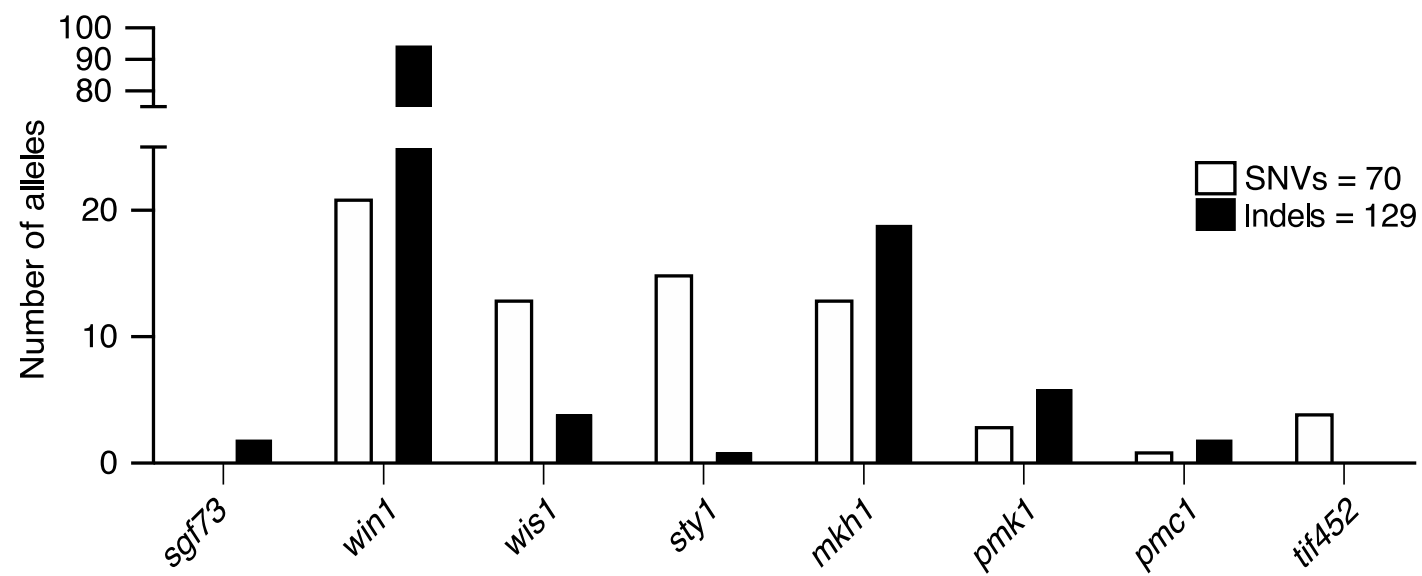

b
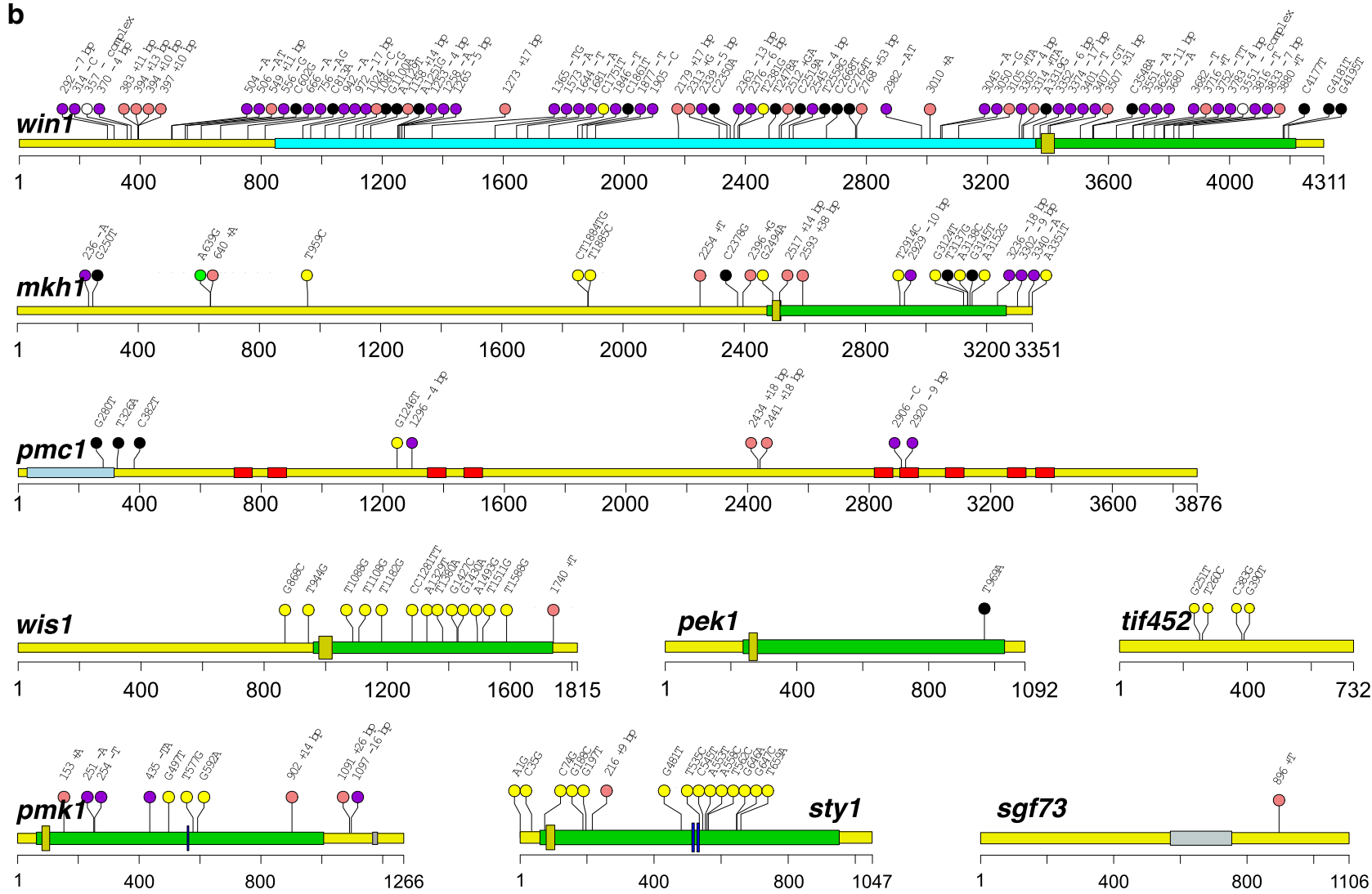

Domains:

$\square$ cDNA

$\square$ ATP binding region

- Short sequence moti

$\square$ Interaction with tea4 $\square$ Protein kinase domain

- Helical-transmembrane region

$\square$ serine - rich

$\square$ SCA7
Mutation types:

Indels: • Deletion

- Insertion

Complex
SNVs: - Nonsense mutation

- Synonymous mutation

- Missense mutation

Fig. 3 Type and position of the mutations found in the genes of interest. a Distribution of the number of SNVs and indels found among the 199 alleles identified by targeted resequencing of cultures 1-3 and subcultures 1-6. In cultures 1-3, mutations found at both 2 and 3 months were counted only once. b Mutations in the nine genes of interest identified by WGS and by targeted resequencing. Known domains and mutation types are indicated.

progenitor) generates a release of nitrogen that primarily benefits the mutant cells. However, the nitrogen concentration released by the dead cells in long-term starved cultures is fluctuating because it is constantly metabolized by viable cells (Supplementary Fig. 2). This hypothesis would also explain why the single cultures of most mutants do not show growth. In this case, nitrogen traces released by dead cells are shared by too many identical mutants, a situation radically different from mutants arising stochastically and progressively.

Scavenging behavior and kin selection. In fission yeast, minimum medium is supplemented with $5 \mathrm{~g} / \mathrm{L}(34 \mathrm{mM})$ of glutamate or ammonium chloride $(93.5 \mathrm{mM})$ while rich medium contains 5 $\mathrm{g} / \mathrm{L}$ of yeast extract. These concentrations allow reaching $10^{8}$ and 
a
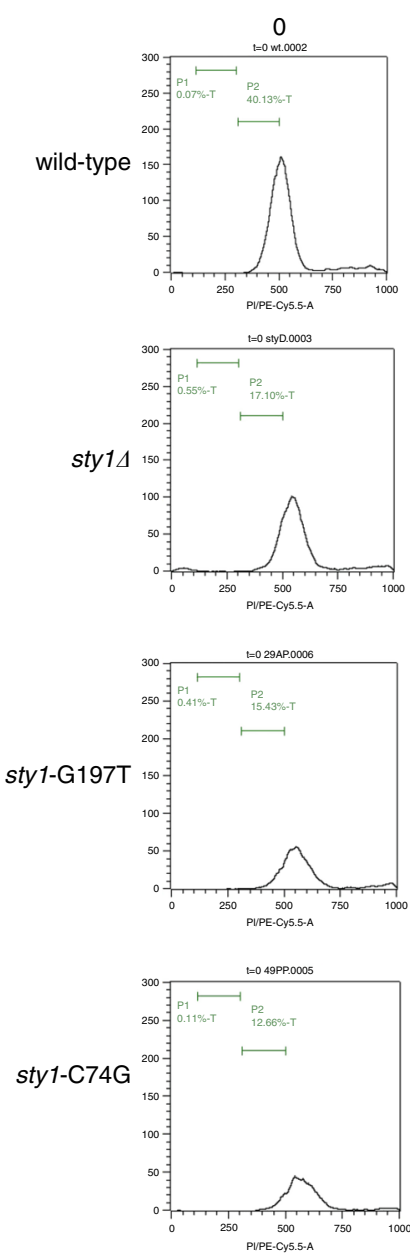

$1 \mathrm{C} 2 \mathrm{C}$
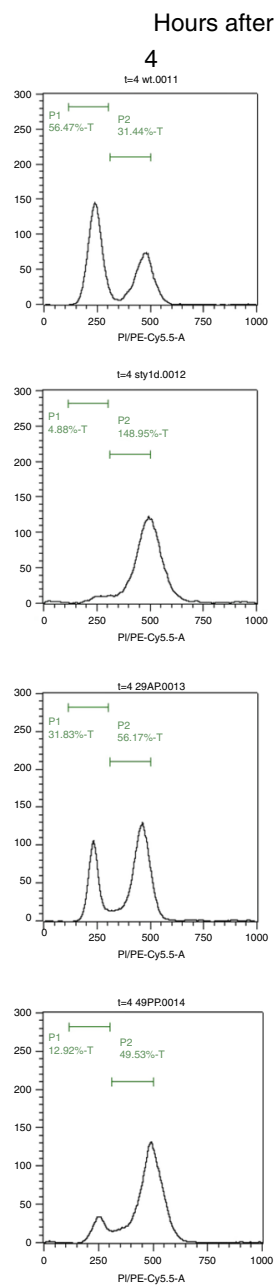

$1 \mathrm{C} 2 \mathrm{C}$
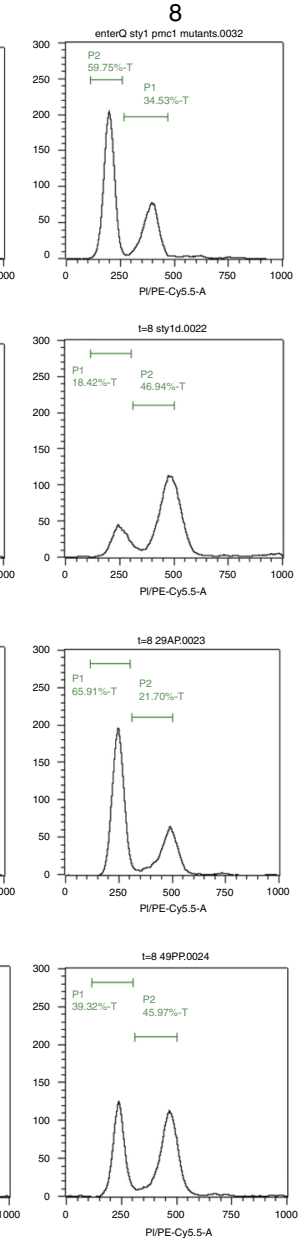

$1 \mathrm{C} 2 \mathrm{C}$

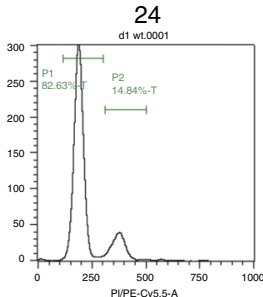

d1 styd.0002
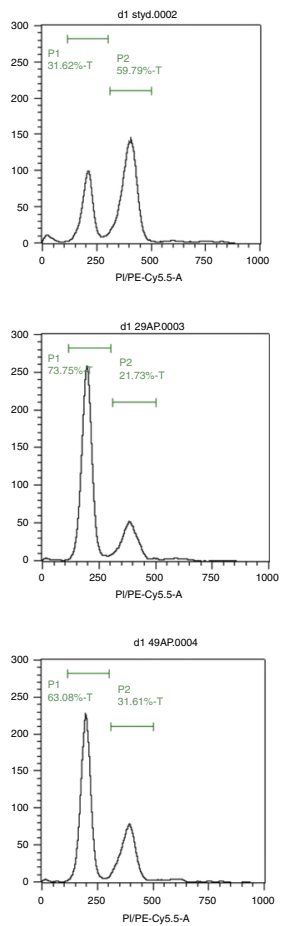

$1 \mathrm{C} 2 \mathrm{C}$ b
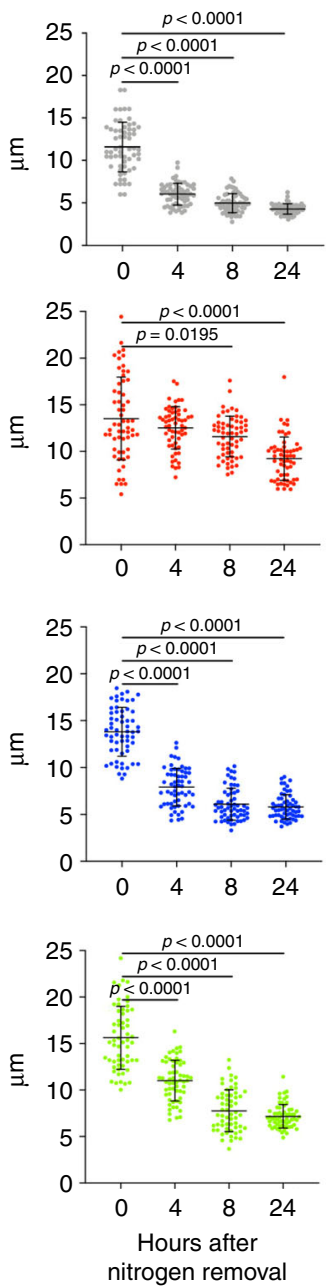

c

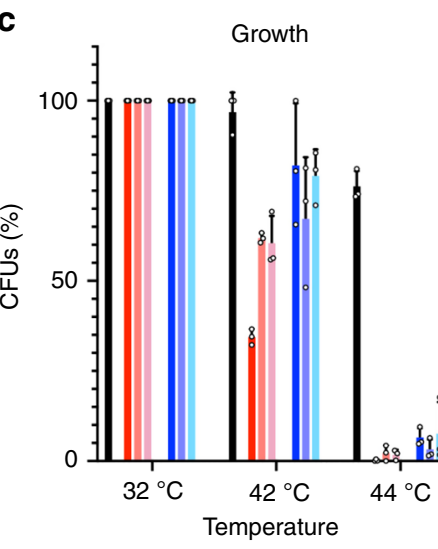

d

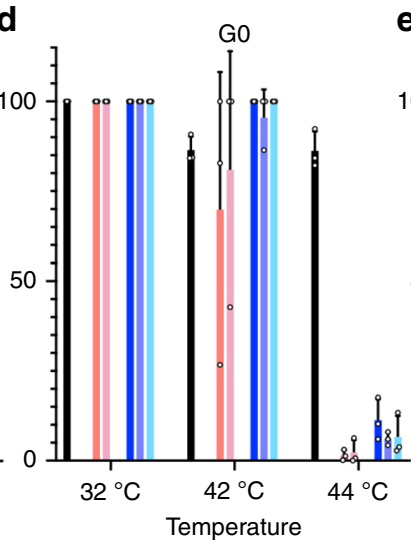

e

wild-type

sty14

sty1-G197T

sty1-C74G

Growth

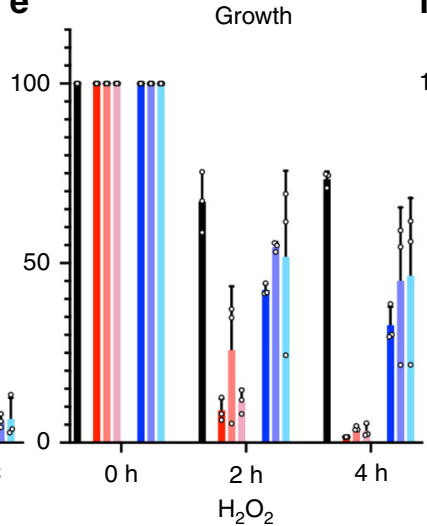

win14 f

Go

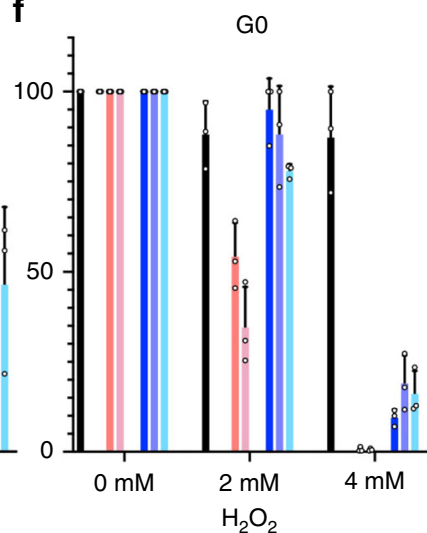

win1-1086 -G

win1-394 +13 bp

Fig. 4 Analysis of quiescence entry and sensitivity to stress. a DNA content analysis after nitrogen removal was determined by FACS. b Cell size determined with Image J on pictures $(n=60)$ after nitrogen removal. The mean and SD are depicted. Two-tailed Mann-Whitney tests were applied and only significant exact $p$ values are shown. Source data are provided as a Source Data file. c The growing strains were incubated for $2 \mathrm{~h}$ at the indicated temperature prior to plating. $\mathbf{d}$ Viability of 1-day-old quiescent strains incubated for $2 \mathrm{~h}$ at the indicated temperature prior to plating. $\mathbf{e}$ Viability of the growing strains following exposure to $1 \mathrm{mM} \mathrm{H}_{2} \mathrm{O}_{2}$ for the indicated times. $\mathbf{f}$ Viability of 1-day-old quiescent strains following exposure for $2 \mathrm{~h}$ to the indicated amounts of $\mathrm{H}_{2} \mathrm{O}_{2}$ prior to plating. After plating on rich medium and incubating at $32{ }^{\circ} \mathrm{C}$ for 3 days, colony-forming units were scored. The values determined at $32{ }^{\circ} \mathrm{C}$, or in the absence of treatment, were set to $100 \%$. The mean, SD, and individual values $(n=3)$ are shown. Source data are provided as a Source Data file. 
a
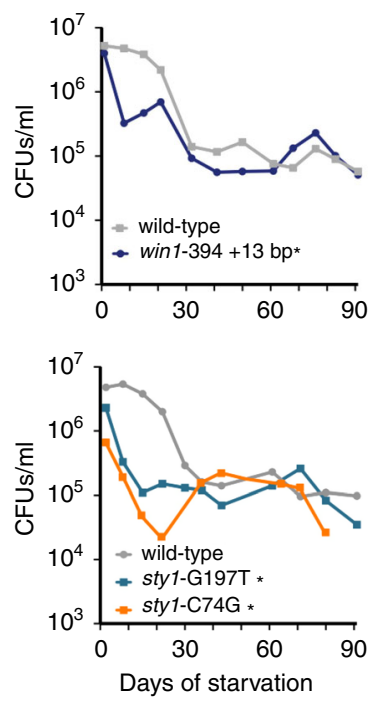
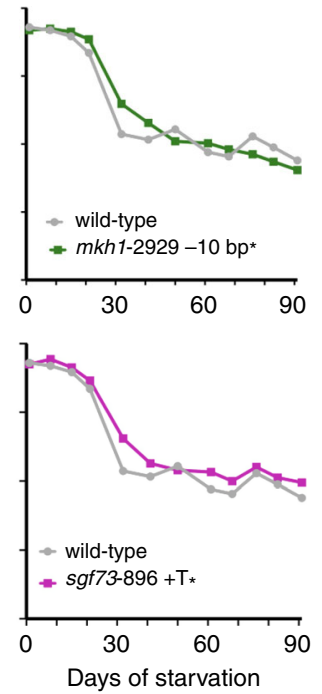

b
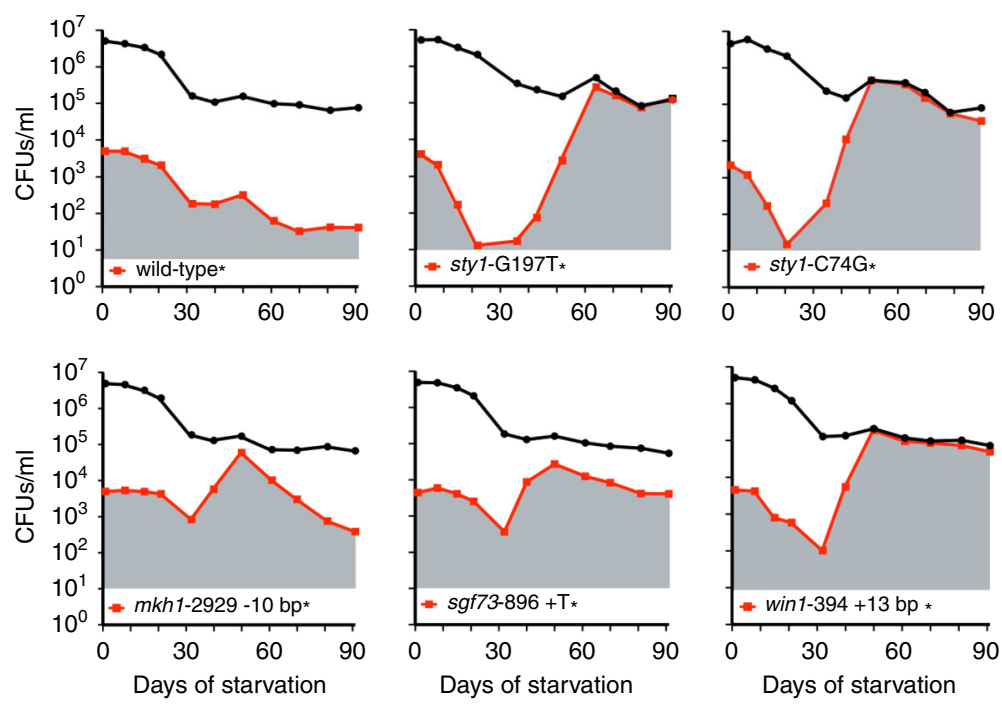

Fig. 5 Survival behavior of the mutants depends on the environment. a Survival of single mutants (colony-forming units) with their wild-type control during long-term starvation. The star $\left(^{*}\right)$ indicates the presence of the kanamycin marker in the background. Source data are provided as a Source Data file. b Co-cultures where the wild-type is contaminated at day 1 of quiescence with $0.1 \%$ of the indicated strain $\left({ }^{\star}\right)$ marked with the kanamycin gene (red). The black curve indicates the viability of the entire population, while the red one reveals the colony-forming units of the kanamycin-resistant strain in this population. Each point corresponds to the mean of independent cultures $(n=2)$, except for the sty1 mutants that were only tested once. Source data are provided as a Source Data file.

$10^{9}$ cells per $\mathrm{mL}$, respectively. To investigate the possibility of a scavenging behavior, we first established by FACS analysis the minimal concentration of glutamate necessary to engage the first $S$ phase is $0.03 \mathrm{mM}$ and that to complete one replication round with no increase in cell number is between 0.09 and $0.12 \mathrm{mM}$ for $4 \times 10^{6}$ wild-type cells per $\mathrm{mL}$ (Supplementary Fig. 2a). Thus, to mimic a slow nitrogen release during an extensive quiescence period, we provided traces of nitrogen by adding either glutamate (0.02 $\mathrm{mM})$, ammonium chloride, or yeast extract to 3 -day-old quiescent cultures (day 0) twice a day for up to 3 days after the first addition (Fig. 6, Methods). The mass $\left(\mathrm{OD}_{600}\right)$, ability to form colonies (CFUs), DNA content by FACS and presence of septa by Calcofluor white staining of wild-type and three mutated downstream players of the S/MAPK pathways ( $s g f 73-896+\mathrm{T}$, sty1G197T and pmk1-869 +A strains) were followed daily (Fig. 6, Supplementary Fig. 3). All the strains increased their cell mass with time, but with no increase in cell number (Fig. 6a, Supplementary Table 6). While the mutants retain their initial number of viable cells (CFUs), the wild-type counterpart progressively forms fewer colonies (Fig. 6a). The analysis of the DNA content indicates that the wild-type cells engage DNA replication with the subsequent appearance of a propidium-negative peak indicative of nuclear DNA degradation (Supplementary Fig. 3, Fig. 6b). Calcofluor white staining reveals the septum of dividing cells. In addition, a large proportion of cells in the wild-type population becomes brightly stained on day 3 after the first addition regardless of the nitrogen source, a phenotype not observed in the mutant cells (Fig. 6c). These Calcofluor bright cells are smooth under phase contrast microscopy and are stained neither by propidium iodide nor by Coomassie blue (Supplementary Fig. 4), indicating that they no longer contain any detectable nucleic acids or proteins. Additionally, the increasing amount of Calcofluor bright cells correlates with the proportion of propidium-negative cells observed by FACS (Supplementary Fig. 4) and identify cells incapable of forming colonies.

In this experiment, the two kinase cascades do not exhibit the same response to low doses of nitrogen. While a subpopulation of sgf73 and pmk1 mutants engages DNA replication, mitosis, septation, and prevents cell death (Fig. 6b, c, Supplementary Fig. 3), the sty 1 mutant delays its first $S$ phase and cell division for 3 days after the first addition (Fig. 6b, c), likely waiting for a higher concentration of nitrogen to become available before engaging DNA replication and septation (Supplementary Fig. 2). Thus, a delayed commitment to DNA replication in situations where nitrogen is scarce can confer a survival and proliferation advantage at quiescence exit. The phenotype of both wild-type and mutant strains are independent of the genetic background, since the segregants from two tetrads of the $p m k 1$ mutant crossed into the $972 \mathrm{~h}^{-}$background exhibit a behavior indistinguishable from that of the strains shown in Fig. 6 upon addition of traces of glutamate (Supplementary Fig. 5). Taken together, these results indicate that a functional SAPK pathway is required to engage rapidly DNA replication upon quiescence exit under suboptimal concentrations of nitrogen, while a proficient MAPK pathway is required for killing the cells that have engaged replication under these conditions. On the contrary, when the concentration of glutamate is brought up to $0.2 \mathrm{mM}$ in a single step in a 3-day-old quiescent culture, all the strains exit quiescence and fully replicate their DNA (Supplementary Fig. 2b), supporting the idea that a slow and progressive release of at least nitrogen by the dying cells promotes the further killing of the wild-type. This scavenging behavior also provides an explanation for the positive clonal advantage of the mutants in the S/MAPK pathways in the presence of parental cells during extended periods of nitrogen starvation.

\section{Discussion}

Using laboratory evolution experiments, we found that mutants related to the S/MAPK response pathway are preferentially recovered upon exit from 2 months of nitrogen-limited conditions and that their appearance becomes predictable. This work is complementary to the previous identification of mutants in systematic screens of deletion libraries coupled with barcode 
a
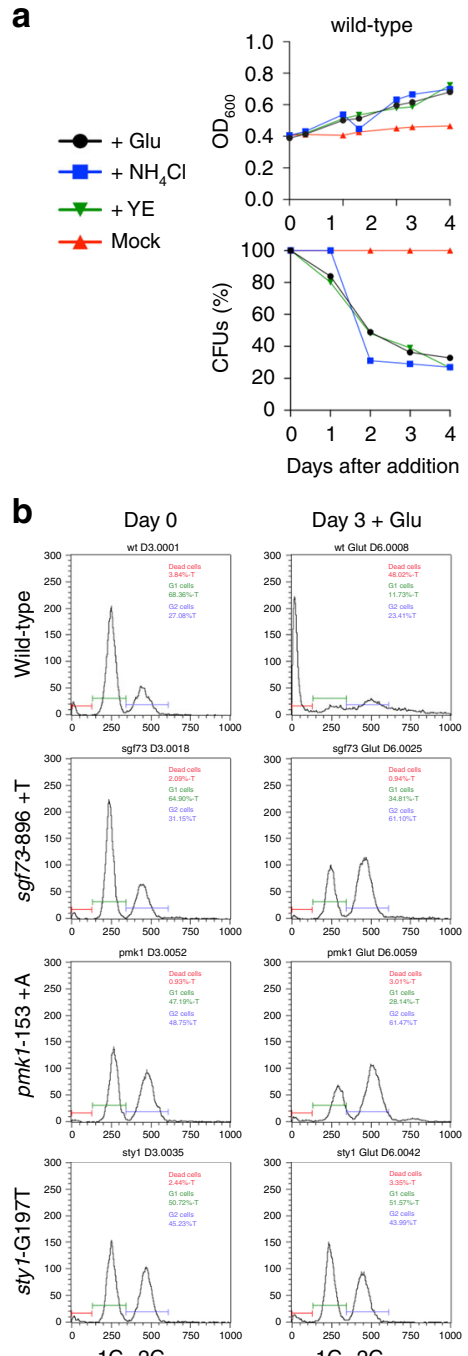

$1 \mathrm{C} 2 \mathrm{C}$

C

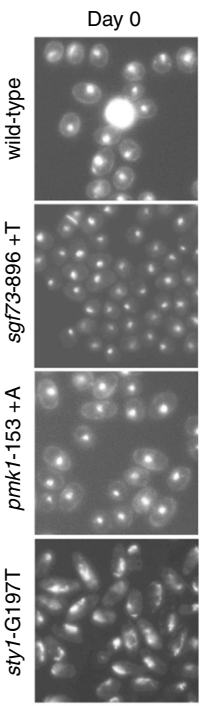

Day $3+$ Glu
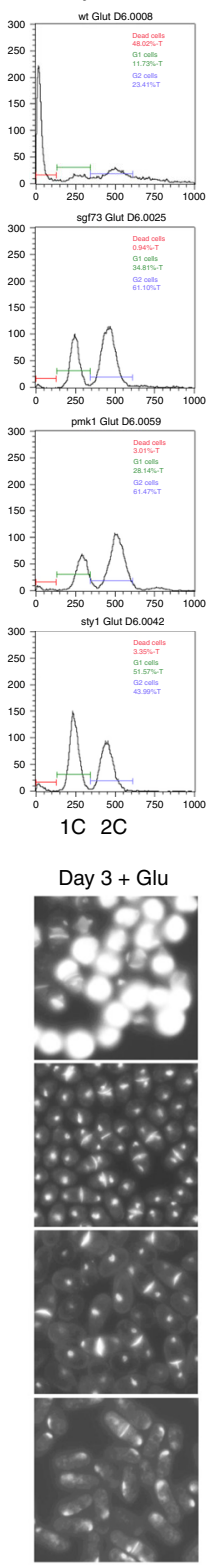

sgf73-896 +T
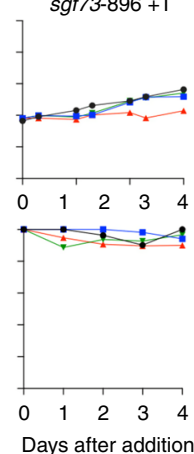

Day $3+\mathrm{NH}_{4} \mathrm{Cl}$
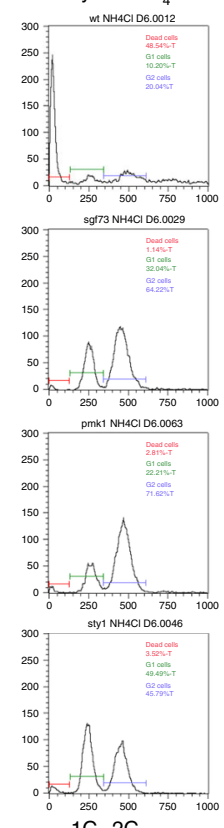

$1 \mathrm{C} 2 \mathrm{C}$

Day $3+\mathrm{NH}_{4} \mathrm{Cl}$

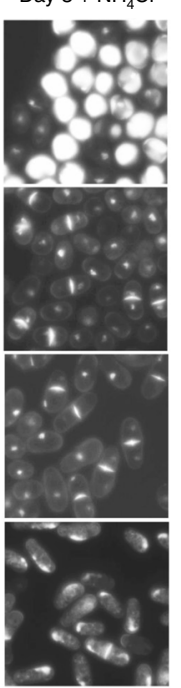

pmk1-153+A
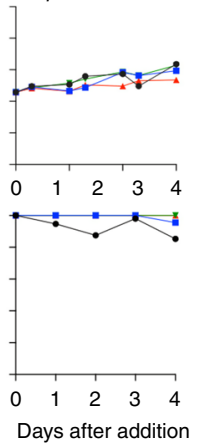

Day $3+Y E$
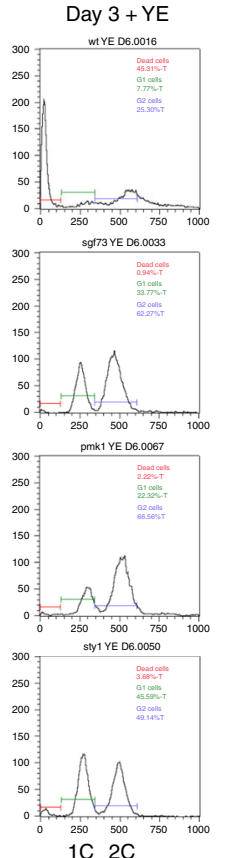

$1 \mathrm{C} 2 \mathrm{C}$
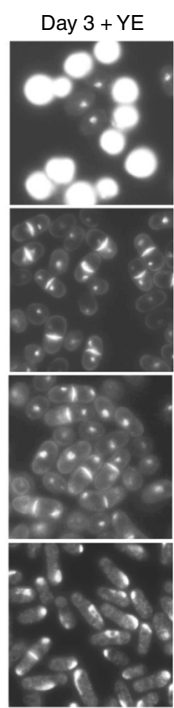

sty1-G197T
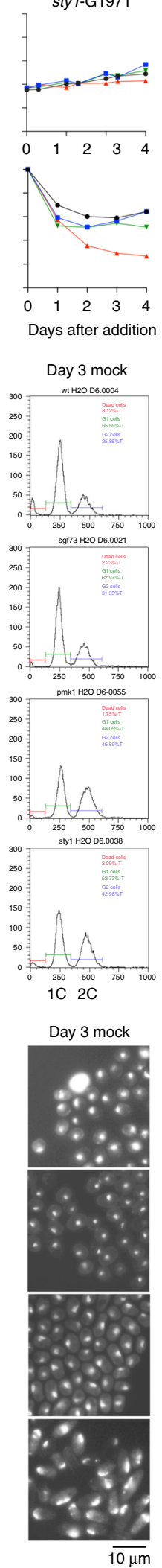

sequencing or of conditional mutants that either sustain quiescence, promote exit, or are resistant to TORC1 inhibition that mimics nitrogen starvation $3,28,38-40$. In the former fission yeast studies, most mutants that have been identified encode proteins associated with membranes and autophagy functions, among which the pek1 mutant (MAPK module) is the only gene shared with this work ${ }^{27,28}$. In budding yeast, high-throughput screening identified HOG1, SSK2 (SAPK pathway), and SGF73 in glucoseand sulfate-limited conditions, respectively ${ }^{32,41}$. Recently, HOG1 was also found mutated in yeast after a 2-year starvation in sealed 
Fig. 6 Scavenging behavior promotes quiescence exit of the S/MAPK mutants. Glutamate, ammonium chloride, or yeast extract was added twice a day to 3-day-old quiescent cultures (day 0 ) containing $4 \times 10^{6}$ cells per $\mathrm{mL}$ at a $1 / 1500$ dilution. The same volume of water was added as a control (mock). a Cell mass increase $\left(\mathrm{OD}_{600 \mathrm{~nm}}\right.$ ) (upper panels) was followed up to day 3 after the first addition; CFUs (lower panels) was determined for up to 4 days after the first addition. The graph corresponds to a representative experiment out of three reproducible and independent ones. $\mathbf{b}$ DNA content analysis was determined by FACS on day 0, prior to nitrogen addition to 3-day-old quiescent cultures, and on day 3 after the first addition. The DNA content by FACS analysis at the intermediate time points of days 1 and 2 after addition are shown in Supplementary Fig. 3. c Fixed cells were stained with a DAPI-Calcofluor solution ( $1 \mu \mathrm{g} / \mathrm{mL} \mathrm{DAPI}, 1 \mu \mathrm{g} / \mathrm{mL} p$-phenylenediamine, $25 \mu \mathrm{g} / \mathrm{mL}$ Calcofluor white) to visualize the nuclei and the septum formation on days 0 and 3 after the first addition. The presented micrographs are representative of the situation observed in the field of 20 pictures each from three independent experiments.

bottles of beer ${ }^{42}$. Thus, mutating the stress-response pathway emerges as a common strategy to promote a growth advantage under different starvation conditions in two unrelated yeast, indicating a high degree of converging evolution ${ }^{43}$. Furthermore, our results indicate that mutations in SAPK and MAPK pathways provide a growth advantage through two different modes: mutating the SAPK module delays $S$ phase entry whereas mutations in the MAPK module ( $p m k 1$ and $s g f 73$ ) protect against cell death (Fig. 6, Supplementary Figs. 3-5).

It is counterintuitive that mutations in the stress-mitogen response pathway provide an advantage in starving and slowdividing cells but other examples have been reported. In several filamentous fungi spore germination is controlled by light, and phytochrome mutants working upstream of the MAP kinase SakA germinate faster than wild-type ${ }^{44}$. In Arabidopsis, the MAPK mpk6 mutant promotes exit from quiescence of the shoot apical meristem ${ }^{45}$. In human and mouse muscles, p38/Sty1 inhibition promotes the proliferation of quiescent satellite cells ${ }^{46}$. In activated lymphocytes, p38/Sty1 deficiency causes hyperproliferation, correlating with a decrease in eIF4E activity ${ }^{47}$. Thus, the S/MAPK mutants can successfully exit from the quiescent state at a lower threshold of environmental or physiological cues. However, the advantage of a rapid exit from nitrogen-limited conditions probably does not compensate for the pleiotropic negative impact of a defect in the S/MAPK pathways, and such runaway mutations are unlikely to become fixed in the population. For instance, two hotspot mutations in sgf73 and $m k h 1$ are located in homonucleotide runs and near low complexity sequences known to be prone to reversion during DNA replication. Finally, the mutations in the nine genes isolated here are not sterile and can therefore be efficiently removed by sexual reproduction with beneficial effects for the population ${ }^{48}$.

The molecular mechanism generating mutations during quiescence in fission yeast is not yet understood, but it was proposed to be due to errors during the repair of spontaneous or induced DNA lesions ${ }^{11,26,27}$. Whereas it is difficult to distinguish whether DNA lesions are processed into mutations during quiescence or become fixed upon resuming DNA replication, multiple lines of evidence support the view that the reported mutations arise and are phenotypically revealed during quiescence. First, according to the well-established replication-dependent mutation rate in wild-type cells ${ }^{23,24}$, the low number of cell divisions $(<27)$ prior to quiescence entry is insufficient to generate the diversity and number of mutants observed in the cultures, while prolonged starvation generates mutations that reach the observed one mutation per genome at 3 months. Second, although biased by selection, the spectrum of mutations determined by whole-genome sequencing (WGS) and to some extent by targeted resequencing is reminiscent of the chronos signature 27 . Third, the variability in distribution, abundance, and type of mutations observed in the six subcultures derived from the same clonal culture supports independent events arising during starvation. Fourth, the death of the mutants during the first month strongly supports the model in which the mutations in the SAPK pathway isolated after 2 months of incubation have arisen during starvation and indicates that the time frame of appearance of a mutation as well as its type (SNVs/indels) and phenotype (recessive/dominant) impact on the expression of the adaptive phenotype; too early, the mutant will die and too late the mutant will be outcompeted by mutants that came up earlier.

Along the same lines, the past decade has registered an accumulation of mutations during the life of microbes or somatic cells that cannot be simply attributed to DNA replication-associated mutagenesis. For Instance, Mycobacterium tuberculosis is spending most of its time in a non-replicative state, motivating geneticists to estimate its mutation rate as a function of time ${ }^{49}$ with a genetic clock producing a similar number of mutations to that observed in fission yeast ${ }^{27}$. In $E$. coli, the stationary phase period is followed by a type of programed cell death and selection of survivors exhibiting the GASP phenotype $e^{50,51}$ that results mainly from mutations reducing the activity of the sigma S/ sigma38 transcription factor (RpoS), the general starvation/stressresponse transcriptional regulator ${ }^{52,53}$. Thus, similarly to the relationship previously proposed for the closely linked mTOR pathway ${ }^{42,54}$, the fission yeast S/MAPK pathway plays a function analogous to RpoS in bacteria. This similarity indicates that the stress-response pathways are central to the genetics of quiescence. In bacteria, in addition to regulating the stress-response genes, RpoS also participates in metabolism rewiring to rapidly adapt to new environments ${ }^{52}$. Importantly, the RpoS-dependent response participates in the starvation/stress-induced mutation process at double-strand DNA breaks by inducing error-prone polymerases $^{55}$ and down-regulating mismatch repair ${ }^{56-58}$, a process that also generates indels (reviewed in ref. ${ }^{54}$ ). However, many different nutritional stresses induce RpoS but with different mutagenic outcomes ${ }^{59}$. The link between hypomorphic rpoS mutations and stress-induced mutagenesis is not clear, but RpoS may itself function as a switch by ultimately being inactivated to limit the effects of mutagenesis associated with the GASP phenotype in an adapted population ${ }^{60}$.

In mammals, increasing evidence supports the notion that somatic cells accumulate clocklike mutations as well ${ }^{61,62}$. Recently, using a targeted resequencing approach, hundreds of NOTCH1 mutations have been found in normal esophageal epithelial cells arising in slow-growing basal cells ${ }^{63}$, a third of which are indels. The abundance and clonal feature of these mutations indicate the occurrence of independent genetic events that promote a positive clonal advantage by triggering differentiation and shedding of the neighboring wild-type cells ${ }^{63,64}$. It was proposed that the prevalence of genetic variants accumulating in a tissuespecific manner may contribute to chronic diseases associated with age by generating a tissue microenvironment with either positive or negative impact on tumor progression ${ }^{65}$. Members of the S/MAPK family are also implicated in genetic instability ${ }^{66}$, and a recent report shows that p38alpha phosphorylates CtIP ${ }^{67}$, a key and early player of double-strand break repair ${ }^{68}$. Finally, future works are needed to explore the emerging idea that starvation/stress-induced mutations may constitute a common 
strategy in microbes and eukaryotes to improve adaptive functions ${ }^{54}$.

In summary, after a prolonged nitrogen-limited incubation fission yeast cells having acquired a mutation in the S/MAPK pathways will exhibit a survival and growth advantage most likely because a sub-limiting amount of nitrogen is continuously released by the surrounding dying cells, fueling the death of more S/MAPK proficient cells. We consider this behavior of a starving population to be an example of kin selection feeding the steadystate number of cells after periods of growth. Self-destruction programs in microbes are not unprecedented and include GASP, thymine-less death as well as diverse antimicrobial strategies in bacteria ${ }^{69-71}$ and have been also reported in yeast and fungi ${ }^{72}$. To conclude, the genetic dynamics of starved cells generate a heterogenous population in which an individual takes over. This situation is observed in microbes as well as in somatic cells during aging and impacts on the resistance to therapies.

\section{Methods}

Long-term nitrogen starvation experiment. The unswitchable M-smt0 haploid prototrophic wild-type strain PB1623 (Table 1) was used throughout this study ${ }^{27}$. Cells were grown in minimal medium $\left(\mathrm{EMM}^{73}\right)$ containing $5 \mathrm{~g} / \mathrm{L}$ of glutamate $(34$ $\mathrm{mM}$ ) up to a cell density below $10^{7}$ cells per $\mathrm{mL}$ and shifted to a minimal medium without nitrogen (EMM-N) containing $4 \%$ glucose at a starting concentration of $10^{6}$ cells per $\mathrm{mL}$. The medium was not replaced during the experiment but the water lost by evaporation during the incubation was compensated for by weighing the culture every week. After 1, 2, and 3 months, the glucose concentration was still around $2 \%$. The ability to form colonies was monitored for 3 months by plating aliquots of the cultures on YES plates at various time points.

Phenotype screening. Survivors were picked and tested for their sensitivity to a range of temperatures, to chemical agents ( $2 \mathrm{M}$ sorbitol, $4 \mathrm{mM}$ hydroxyurea, $0.01 \%$ SDS, $14 \mu \mathrm{g} / \mathrm{mL}$ Thiabendazole) and to a high concentration of salts $(0.8 \mathrm{M} \mathrm{KCl}$ and $0.3 \mathrm{M} \mathrm{CaCl}_{2}$ ) that do not affect the growth of wild-type cells. Drop assays starting with $10^{4}$ cells per drop with fivefold serial dilutions were spotted onto YES plates containing a selective agent and incubated for 3-4 days at $32{ }^{\circ} \mathrm{C}$. They were subjected to secondary testing using a different batch of the medium, and only those recapitulating the sensitivity were kept. The presence of the mutations in the targeted resequencing experiment was confirmed by plating out 120 cells per pool and scoring for their sensitivity to temperature, calcium, HU, and SDS. The DNA of the sensitive colonies was prepared and used to amplify the relevant target genes. Sanger sequencing of the fragments confirmed the presence of several mutations in the various pools (alleles in red in Fig. 2 and Supplementary Table 5).

Targeted resequencing. Three independent $10 \mathrm{~mL}$ cultures or one $60 \mathrm{~mL}$ culture with the minimum number of cell divisions $(<27)$ required to generate $4 \times 10^{6}$ quiescent cells per $\mathrm{mL}$ (cultures 1-3, and subcultures 1-6) were grown with the smallest possible level of mutation. We isolated and froze 1000 colonies, by pools of 100 colonies after 60 (cultures $0-3$ and subcultures 1-6) and 90 days (cultures 0-3) of quiescence (Fig. 2a). Similarly, 1000 colonies were also picked at day 1 from cultures 1-3 and the subculture. To collect a similar number of cells for each colony $\left(\sim 5 \times 10^{6}\right.$ cells), colonies of a similar size were taken after 3 days and 4 days for the small colonies. The pools were stored at $-80^{\circ} \mathrm{C}$ in $20 \%$ glycerol. From each pool, approximately $2.5 \times 10^{7}$ cells were used for standard DNA extraction. Each individual PCR product was purified after separation on agarose gels and quantified. Barcoded adapter primers were added to generate the libraries. To cover the genes of interest, primer pairs were designed (Supplementary Table 7) to generate overlapping PCR fragments of an average size of 420 base pairs. PCR reactions were performed with the Q5 high-fidelity polymerase Master Mix (New England Biolabs) according to the manufacturer's recommendations. Each PCR reaction was performed in duplicate to generate two independent batches making it possible to exclude few variants due to errors occurring during the amplification process. The amount of each PCR product was estimated on agarose gels and adjusted to the lowest concentration. Next, equal volumes of normalized PCR products from each sample were pooled and purified using the QIAGEN PCR purification kit following the manufacturer's recommendations. The analysis workflow is described in Supplementary Methods.

Fluorescent-activated cell sorting. $4 \times 10^{6}$ cells $(1 \mathrm{~mL})$ were harvested and resuspended in $1 \mathrm{~mL}$ cold $70 \%$ ethanol overnight at $-20^{\circ} \mathrm{C}$. Cells are washed in 50 $\mathrm{mM}$ sodium citrate $(\mathrm{pH} \mathrm{7})$ for $15 \mathrm{~min}$ and resuspended in $0.5 \mathrm{~mL}$ of $50 \mathrm{mM}$ sodium citrate, containing $0.1 \mathrm{mg} / \mathrm{mL}$ RNase A for $2 \mathrm{~h}$ at $37^{\circ} \mathrm{C}$. Next, we added 0.5 $\mathrm{mL}$ sodium citrate, containing $4 \mu \mathrm{g} / \mathrm{mL}$ of propidium iodide. The analysis was performed on 10,000 cells with a MACSQuant Analyzer (Miltenyi) and MACSQuantify software, and no gating was applied.
Co-cultures. Mutants and wild-type cells were grown separately in EMM prior to transferring to EMM-N. At day 1 of quiescence, the wild-type culture was contaminated with the mutant at $0.1 \%$. The kanamycin-resistance cassette was inserted at the chromosomal locus chr2SPBC31A8.02 to mark the mutants, making them readily identifiable. The proportion of kanamycin-resistant colonies was monitored during nitrogen starvation by plating weekly aliquots of the co-culture on YES plates and YES plates supplemented with kanamycin during the 3 months of the experiment.

Triggering quiescence exit. To trigger quiescence exit in the absence of cell division, glutamate was added twice a day in the morning and in the evening, at a starting concentration of $20 \mu \mathrm{M}$ and reaching a maximum concentration of $200 \mu \mathrm{M}$ after 10 additions, if none of the glutamate is metabolized. For ammonium chloride ( $1.6 \mathrm{~g} / \mathrm{L}$-amount of nitrogen similar to that of glutamate) and yeast extract ( $5 \mathrm{~g} / \mathrm{L})$, the same dilution and procedure were used. Water was used as control (mock). Cell mass was monitored by $\mathrm{OD}_{600}$, cell number by Beckman Coulter Z1 Particle Counter, and CFUs by plating onto YES plates. DNA content was determined on ethanol-fixed cells using FACS. For microscopy, cells were stained with a DAPICalcofluor solution $(2 \mu \mathrm{g} / \mathrm{mL}$ DAPI, $1 \mu \mathrm{g} / \mathrm{mL}$ p-phenylenediamine, $25 \mu \mathrm{g} / \mathrm{mL} \mathrm{Cal-}$ cofluor white) to visualize the nuclei and the septum formation with a Zeiss Axioplan 2 Imaging $M$ epifluorescence microscope.

Reporting summary. Further information on research design is available in the Nature Research Reporting Summary linked to this article.

\section{Data availability}

Sequence data that support the findings of this study have been deposited in BioProject ID with the accession code PRJNA604512 (NIH SRA). The source data underlying Figs. $1 \mathrm{a}, 4 \mathrm{~b}-\mathrm{f}, 5 \mathrm{a}, \mathrm{b}$ are provided as a Source Data file.

Received: 5 September 2019; Accepted: 24 March 2020; Published online: 24 April 2020

\section{References}

1. Koch, A. L. The adaptive responses of Escherichia coli to a feast and famine existence. Adv. Microb. Physiol. 6, 147-217 (1971).

2. Yanagida, M., Ikai, N., Shimanuki, M. \& Sajiki, K. Nutrient limitations alter cell division control and chromosome segregation through growth-related kinases and phosphatases. Philos. Trans. R. Soc. B 366, 3508-3520 (2011).

3. Roche, B., Arcangioli, B. \& Martienssen, R. A. RNA interference is essential for cellular quiescence. Science 354, https://doi.org/10.1126/science.aah5651 (2016).

4. Maestroni, L., Matmati, S., Arcangioli, B., Géli, V. \& Coulon, S. Eroded telomeres are rearranged in quiescent fission yeast cells through duplications of subtelomeric sequences. Nat. Commun. 8, 825, https://doi.org/10.1038/ s41467-017-01894-6 (2017).

5. Joh, R. I. et al. Survival in quiescence requires the euchromatic deployment of Clr4/SUV39H by argonaute-associated small RNAs. Mol. Cell 64, 1088-1101 (2016).

6. Fabrizio, P. \& Longo, V. D. The chronological life span of Saccharomyces cerevisiae. Aging Cell 2, 73-81 (2003).

7. Gray, J. V. et al. 'Sleeping beauty': quiescence in Saccharomyces cerevisiae. Microbiol. Mol. Biol. Rev. 68, 187-206 (2004).

8. Chen, B. R. \& Runge, K. W. A new Schizosaccharomyces pombe chronological lifespan assay reveals that caloric restriction promotes efficient cell cycle exit and extends longevity. Exp. Gerontol. 44, 493-502 (2009).

9. Nunez, A., Dulude, D., Jbel, M. \& Rokeach, L. A. Calnexin is essential for survival under nitrogen starvation and stationary phase in Schizosaccharomyces pombe. PLoS ONE 10, e0121059, https://doi.org/10.1371/ journal.pone.0121059 (2015).

10. Encinar del Dedo, J., Gabrielli, N., Carmona, M., Ayté, J. \& Hidalgo, E. A cascade of iron-containing proteins governs the genetic iron starvation response to promote iron uptake and inhibit iron storage in fission yeast. PLoS Genet. 11, e1005106, https://doi.org/10.1371/journal.pgen.1005106 (2015).

11. Mochida, S. \& Yanagida, M. Distinct modes of DNA damage response in $S$. pombe G0 and vegetative cells. Genes Cells 11, 13-27 (2005).

12. Petrini, E. et al. A new phosphate-starvation response in fission yeast requires the endocytic function of myosin I. J. Cell Sci. 128, 3707-3713 (2015).

13. Su, S. S., Tanaka, Y., Samejima, I., Tanaka, T. \& Yanagida, M. A nitrogen starvation-induced dormant G0 state in fission yeast: the establishment from uncommitted G1 state and its delay for return to proliferation. J. Cell Sci. 109 (Pt 6), 1347-1357 (1996).

14. Yanagida, M. Cellular quiescence: are controlling genes conserved? Trends Cell Biol. 19, 705-715 (2009). 
15. Petersen, J. \& Nurse, P. TOR signalling regulates mitotic commitment through the stress MAP kinase pathway and the Polo and Cdc2 kinases. Nat. Cell Biol. 9, 1263-1272 (2007).

16. Sajiki, K. et al. Genetic control of cellular quiescence in S. pombe. J. Cell Sci. 122, 1418-1429 (2009).

17. Gangloff, S. \& Arcangioli, B. DNA repair and mutations during quiescence in yeast. FEMS Yeast Res. 17, 742, https://doi.org/10.1093/femsyr/fox002 (2017).

18. Marguerat, S. et al. Quantitative analysis of fission yeast transcriptomes and proteomes in proliferating and quiescent cells. Cell 151, 671-683 (2012).

19. Madrid, M. et al. Stress-induced response, localization, and regulation of the Pmk1 cell integrity pathway in Schizosaccharomyces pombe. J. Biol. Chem. 281, 2033-2043 (2006).

20. Zhou, X., Ma, Y., Kato, T. \& Kuno, T. A measurable activation of the bZIP transcription factor Atfl in a fission yeast strain devoid of stress-activated and cell integrity mitogen-activated protein kinase (MAPK) activities. J. Biol. Chem. 287, 23434-23439 (2012).

21. Luria, S. E. \& Delbrück, M. Mutations of bacteria from virus sensitivity to virus resistance. Genetics 28, 491-511 (1943).

22. Lea, D. E. \& Coulson, C. A. The distribution of the numbers of mutants in bacterial populations. J. Genet. 49, 264-285 (1949).

23. Farlow, A. et al. The spontaneous mutation rate in the fission yeast Schizosaccharomyces pombe. Genetics 201, 737-744 (2015).

24. Behringer, M. G. \& Hall, D. W. Genome-wide estimates of mutation rates and spectrum in Schizosaccharomyces pombe indicate CpG sites are highly mutagenic despite the absence of DNA methylation. G3 (Bethesda) 6, 149-160, https://doi.org/10.1534/g3.115.022129 (2015).

25. Lynch, M. Rate, molecular spectrum, and consequences of human mutation. Proc. Natl. Acad. Sci. USA 107, 961-968 (2010).

26. Ben Hassine, S. \& Arcangioli, B. Tdp1 protects against oxidative DNA damage in non-dividing fission yeast. EMBO J. 28, 632-640 (2009).

27. Gangloff, S. et al. Quiescence unveils a novel mutational force in fission yeast. Elife 6, https://doi.org/10.7554/eLife.27469 (2017).

28. Sideri, T. et al. Parallel profiling of fission yeast deletion mutants for proliferation and for lifespan during long-term quiescence. G3 (Bethesda) $\mathbf{5}$, 145-155, https://doi.org/10.1534/g3.114.014415 (2014).

29. Drake, J. W., Bebenek, A., Kissling, G. E. \& Peddada, S. Clusters of mutations from transient hypermutability. Proc. Natl. Acad. Sci. USA 102, 12849-12854 (2005).

30. Ptushkina, M., Malys, N. \& McCarthy, J. E. G. eIF4E isoform 2 in Schizosaccharomyces pombe is a novel stress-response factor. EMBO Rep. 5, 311-316 (2004).

31. Mason, A. G. et al. The replicative lifespan-extending deletion of SGF73 results in altered ribosomal gene expression in yeast. Aging Cell 16, 785-796 (2017).

32. Hickman, M. J., Spatt, D. \& Winston, F. The Hog1 mitogen-activated protein kinase mediates a hypoxic response in Saccharomyces cerevisiae. Genetics $\mathbf{1 8 8}$, 325-338 (2011).

33. Ishiguro, J., Shibahara, K., Ueda, Y. \& Nakamura, K. Fission yeast TOR signaling is essential for the down-regulation of a hyperactivated stressresponse MAP kinase under salt stress. Mol. Genet. Genomics 288, 63-75 (2013).

34. Deng, L. et al. Real-time monitoring of calcineurin activity in living cells: evidence for two distinct Ca2+-dependent pathways in fission yeast. Mol. Biol. Cell 17, 4790-4800 (2006).

35. Samejima, I., Mackie, S., Warbrick, E., Weisman, R. \& Fantes, P. A. The fission yeast mitotic regulator win1+ encodes an MAP kinase kinase kinase that phosphorylates and activates Wis1 MAP kinase kinase in response to high osmolarity. Mol. Biol. Cell 9, 2325-2335 (1998).

36. Tabassum, D. P. \& Polyak, K. Tumorigenesis: it takes a village. Nat. Rev. Cancer 15, 473-483 (2015).

37. Zambrano, M. M., Siegele, D. A., Almirón, M., Tormo, A. \& Kolter, R. Microbial competition: Escherichia coli mutants that take over stationary phase cultures. Science 259, 1757-1760 (1993).

38. Rallis, C., Lopez-Maury, L., Georgescu, T., Pancaldi, V. \& Bahler, J. Systematic screen for mutants resistant to TORC1 inhibition in fission yeast reveals genes involved in cellular ageing and growth. Biol. Open 3, 161-171 (2014).

39. Sajiki, K. et al. Genetic regulation of mitotic competence in G0 quiescent cells. Sci. Adv. 4, eaat5685, https://doi.org/10.1126/sciadv.aat5685 (2018).

40. Irvine, D. V. et al. Mapping epigenetic mutations in fission yeast using wholegenome next-generation sequencing. Genome Res. 19, 1077-1083 (2009).

41. Payen, C. et al. High-throughput identification of adaptive mutations in experimentally evolved yeast populations. PLoS Genet. 12, e1006339, https:// doi.org/10.1371/journal.pgen.1006339 (2016).

42. Aouizerat, T. et al. Eukaryotic adaptation to years-long starvation resembles that of bacteria. iScience 19, 545-558 (2019).

43. Bailey, S. F., Guo, Q. \& Bataillon, T. Identifying drivers of parallel evolution: a regression model approach. Genome Biol. Evol. 10, 2801-2812 (2018).

44. Yu, Z., Armant, O. \& Fischer, R. Fungi use the SakA (HogA) pathway for phytochrome-dependent light signalling. Nat. Microbiol. 1, 585 (2016).
45. Dóczi, R. et al. The MKK7-MPK6 MAP kinase module is a regulator of meristem quiescence or active growth in Arabidopsis. Front. Plant Sci. 10, 302, https://doi.org/10.3389/fpls.2019.00202 (2019).

46. Charville, G. W. et al. Ex vivo expansion and in vivo self-renewal of human muscle stem cells. Stem Cell Rep. 5, 621-632 (2015).

47. Salvador-Bernaldez, M. et al. p38a regulates cytokine-induced IFN $\gamma$ secretion via the Mnk1/eIF4E pathway in Th1 cells. Immunol. Cell Biol. 95, 814-823 (2017).

48. Ram, Y. \& Hadany, L. Stress-induced mutagenesis and complex adaptation. Proc. Biol. Sci. 281, 20141025 (2014).

49. Ford, C. B. et al. Mycobacterium tuberculosis mutation rate estimates from different lineages predict substantial differences in the emergence of drugresistant tuberculosis. Nat. Genet. 45, 784-790 (2013).

50. Zinser, E. R. \& Kolter, R. Escherichia coli evolution during stationary phase. Res. Microbiol. 155, 328-336 (2004).

51. Finkel, S. E. Long-term survival during stationary phase: evolution and the GASP phenotype. Nat. Rev. Microbiol. 4, 113-120 (2006).

52. Battesti, A., Majdalani, N. \& Gottesman, S. The RpoS-mediated general stress response in Escherichia coli. Annu. Rev. Microbiol. 65, 189-213 (2011).

53. Ferenci, T. What is driving the acquisition of $m u t S$ and $r p o S$ polymorphisms in Escherichia coli? Trends Microbiol. 11, 457-461 (2003).

54. Fitzgerald, D. M., Hastings, P. J. \& Rosenberg, S. M. Stress-induced mutagenesis: implications in cancer and drug resistance. Annu. Rev. Cancer Biol. 1, 119-140 (2017).

55. Layton, J. C. \& Foster, P. L. Error-prone DNA polymerase IV is controlled by the stress-response sigma factor, RpoS, in Escherichia coli. Mol. Microbiol. 50, 549-561 (2003).

56. Tsui, H. C. T., Feng, G. \& Winkler, M. E. Negative regulation of mutS and mutH repair gene expression by the $\mathrm{Hfq}$ and RpoS global regulators of Escherichia coli K-12. J. Bacteriol. 179, 7476-7487 (1997).

57. Tenaillon, O., Denamur, E. \& Matic, I. Evolutionary significance of stressinduced mutagenesis in bacteria. Trends Microbiol. 12, 264-270 (2004).

58. Ponder, R. G., Fonville, N. C. \& Rosenberg, S. M. A switch from high-fidelity to error-prone DNA double-strand break repair underlies stress-induced mutation. Mol. Cell 19, 791-804 (2005).

59. Ferenci, T. Irregularities in genetic variation and mutation rates with environmental stresses. Environ. Microbiol. 21, 3979-3988 (2019).

60. Galhardo, R. S., Hastings, P. J. \& Rosenberg, S. M. Mutation as a stress response and the regulation of evolvability. Crit. Rev. Biochem. Mol. Biol. 42, 399-435 (2008).

61. Alexandrov, L. B. et al. Clock-like mutational processes in human somatic cells. Nat. Genet. 47, 1402-1407 (2015).

62. Blokzijl, F. et al. Tissue-specific mutation accumulation in human adult stem cells during life. Nature 538, 260-264 (2016).

63. Martincorena, I. et al. Somatic mutant clones colonize the human esophagus with age. Science 362, 911-917 (2018).

64. Alcolea, M. P. \& Jones, P. H. Cell competition: winning out by losing notch Cell Cycle 14, 9-17 (2015)

65. Chanock, S. J. The paradox of mutations and cancer. Science 362, 893-894 (2018).

66. Köpper, F. et al. Damage-induced DNA replication stalling relies on MAPKactivated protein kinase 2 activity. Proc. Natl. Acad. Sci. USA 110, 16856-16861 (2013)

67. Canovas, B. et al. Targeting p38a increases DNA damage, chromosome instability, and the anti-tumoral response to taxanes in breast cancer cells. Cancer Cell 33, 1094-1110.e8, https://doi.org/10.1016/j.ccell.2018.04.010 (2018).

68. Lloyd, J. et al. A supramodular FHA/BRCT-repeat architecture mediates Nbs1 adaptor function in response to DNA damage. Cell 139, 100-111 (2009).

69. Trastoy, R. et al. Mechanisms of bacterial tolerance and persistence in the gastrointestinal and respiratory environments. Clin. Microbiol. Rev. 31, 343 https://doi.org/10.1128/CMR.00023-18 (2018).

70. Engelberg-Kulka, H., Amitai, S., Kolodkin-Gal, I. \& Hazan, R. Bacterial programmed cell death and multicellular behavior in bacteria. PLoS Genet. 2, e135, https://doi.org/10.1371/journal.pgen.0020135 (2006).

71. Hong, Y., Li, L., Luan, G., Drlica, K. \& Zhao, X. Contribution of reactive oxygen species to thymineless death in Escherichia coli. Nat. Microbiol. 2, 1667-1675 (2017)

72. Gonçalves, A. P., Heller, J., Daskalov, A., Videira, A. \& Glass, N. L. Regulated forms of cell death in fungi. Front. Microbiol. 8, 151, https://doi.org/10.3389/ fmicb.2017.01837 (2017).

73. Moreno, S., Klar, A. J. S. \& Nurse, P. Molecular genetic analysis of fission yeast Schizosaccharomyces pombe. Methods Enzymol. 194, 795-823 (1991).

\section{Acknowledgements}

R.M. was supported by the Pasteur-Paris Sorbonne Universite (PPU) International PhD Program (E515 de Sorbonne Université) and La Ligue Nationale contre le Cancer. This 
work was supported by the CNRS, the Institut Pasteur and the ANR-13-BSV8-0018 grant. We thank Julianne Smith for the critical reading of the manuscript.

\section{Author contributions}

Conceptualization, B.A. Software, R.M. and S.G. Formal analysis, R.M., S.F., and S.G. Investigation, R.M., C.D., S.G., and S.F. Data curation, R.M. and S.G. Writing, S.F., S.G., and B.A. Data visualization, R.M., C.D., S.F., S.G., and B.A. Supervision, B.A. Project administration, B.A. Funding acquisition, B.A.

\section{Competing interests}

The authors declare no competing interests.

\section{Additional information}

Supplementary information is available for this paper at https://doi.org/10.1038/s41467$020-15880-y$.

Correspondence and requests for materials should be addressed to B.A.

Peer review information Nature Communications thanks the anonymous reviewer(s) for their contribution to the peer review of this work. Peer reviewer reports are available.
Reprints and permission information is available at http://www.nature.com/reprints

Publisher's note Springer Nature remains neutral with regard to jurisdictional claims in published maps and institutional affiliations.

\section{(c) (i)}

Open Access This article is licensed under a Creative Commons Attribution 4.0 International License, which permits use, sharing, adaptation, distribution and reproduction in any medium or format, as long as you give appropriate credit to the original author(s) and the source, provide a link to the Creative Commons license, and indicate if changes were made. The images or other third party material in this article are included in the article's Creative Commons license, unless indicated otherwise in a credit line to the material. If material is not included in the article's Creative Commons license and your intended use is not permitted by statutory regulation or exceeds the permitted use, you will need to obtain permission directly from the copyright holder. To view a copy of this license, visit http://creativecommons.org/ licenses/by/4.0/.

(C) The Author(s) 2020 